\title{
STRUCTURAL PERFORMANCE OF SANDWICH PANEL UNDER POINT LOAD
}

\author{
M .Nawar ${ }^{1}$, B. Eltaly ${ }^{2}$ and K. Kandeel ${ }^{3}$ \\ ${ }^{I}$ MSc student, Civil Engineering Department, Faculty of Engineering, Minoufia University, Egypt. \\ ${ }^{2}$ Lecturer, Civil Engineering Department, Faculty of Engineering, Minoufia University, Egypt. \\ ${ }^{3}$ Professor, Civil Engineering Department, Faculty of Engineering, Minoufia University, Egypt.
}

\begin{abstract}
This paper presents the results of the experimental program of three type of sandwich panel; corrugated, web, two-directional corrugated core sandwich panel. Also the current research developed finite element models to simulate the three tested panel under point load up to failure and the model was verified by comparing the results with those obtained from the tests. The numerical simulation gives a better understanding of the behavior of the three types of panel under the point load in terms of the internal forces, deflection and failure modes of the different parts, the top skin, the bottom skin and the core.

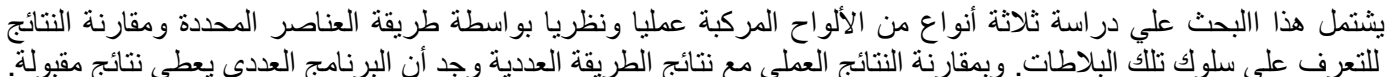

Keywords: sandwich panel; wrinkling; intercellular buckling, finite element method; non-linear analysis.

\section{1- INTRODUCTION}

The sandwich concept significantly reduces weight and increases stiffness of the structure while maintaining their strength. Sandwich panels cover lightweight aerospace structures, marine structures, hollow structural shells, and conventional building walls, roofs and floors (Langhorst (2008)). They consist of stiff and strong face sheets (skins) separated by a low density core. The core is bonded to the skins with an adhesive or with metal components by brazing together. The face sheet carries bending loads while the core supports transverse shear and through-thickness indentation loads. Sheet metal is common used as skin material (Liu et al. (2008)). Also Laminates of glass (Manalo et al. 2010)), glass fibre reinforced polymer (Awad et al, 2012)), carbon fiber-reinforced thermoplastics or mainly thermoset polymers; unsaturated polyesters, epoxies as example (Engin and Rizkalla (2008) and Fam and Sharaf (2010)) are widely used as skin materials. There are various types of core panels; foam, metal, corrugated, web, honeycomb, folded and trussed core panels (Godfrey (2010)). Foams core may be polyvinylchloride, polyurethane, polyethylene or polystyrene materials. Folded cores gained new interest from the industry to overcome the drawbacks of the honeycomb cores. The honeycomb cores are an expensive material because of their iterative production process. Also their cells are closed which makes them prone to store water condensation during successive take-off and landing of airplanes. This water damages the bound between core and skin and caused unexpected de-laminations (El-Sayed and Basily (2004).

There are three major approaches considered for the analysis of sandwich panels. In the first one, the actual layered panel is replaced by an equivalent one with a single layer (equivalent single layer) with equivalent properties (Sokolinsky and Frostig (2000)). In the second approach, the layered configuration is assumes to consist of a core that is incompressible and is infinitely stiff in the vertical direction (Frostig (2003)). The third approach takes into account the vertical flexibility of the core. The results of third categories give the actual behavior of the sandwich panel (Frostig (2009)). Briscoe et al. (2010) investigated a numerical model to study the buckling behavior of inter web while the inter web is used to improve the buckling behavior of the sandwich panel. In their model, the webs are modeled as simply supported plates. This plate rests on a Pasternak elastic foundation. Pokharel and Mahendran (2004) presented the results of experimental models on 50 foam-supported steel plate elements under bending up to failure. Also they developed finite element models using ABAQUS program to simulate the tested panels. Their numerical model gives good results comparing with 
their experimental results. Leekitwattana et al. (2011) presented a new concept in steel corrugated core to derive the equivalent transverse shear stiffness of them. Jeffrey et al. (2013) studied experimentally steel sandwich panels consist of prismatic V-cores. Their cores panels were bonded to the facings using laser stake welds. Candidate sandwich panel designs were analyzed using geometrically nonlinear finite element analysis (ABAQUS program). The finite element model gives accepted results comparing with their experimental.

Wrinkling phenomenon is a series of short wave buckles develop first in the compression steel face and the wrinkling failure follows when one of the buckles collapses (Hadi and Matthews (2000) and Gdoutos et al. (2003)). Numerous studies carried out to study this phenomenon in sandwich panel. Pokharel and Mahendran (2005) studied lightly profiled sandwich panels. They concluded that local buckling of flat plate elements is the critical failure mode for fully profiled sandwich panels. On the other hand flat panels undergo a flexural wrinkling type failure. In lightly profiled faces, the interaction between the local buckling and flexural wrinkling are taken place. Biagi et al. (2012) investigated an analytical model and an experimental program to estimate the in-plane compressive response of corrugated core sandwich columns. They concluded that the failure mechanisms for the in-plane loading of a corrugated core sandwich column have been included macro buckling, shear buckling and face wrinkling.

The current research presents an experimental program for manufacturing and testing three different types of sandwich panel. The three types have the same steel skins but different core type; corrugated, web and twodirectional corrugated core. Also Finite Element (FE) models were developed using ANSYS package (2006) to study the three tested type up to failure. These models considered the geometry and the material nonlinearity in consideration. Furthermore, the results of FE models were verified with the experimental results.

\section{EXPERIMENTAL WORK}

Three different types of sandwich panels were manufactured and tested in workshops and reinforced concrete laboratory of Faculty of EngineeringMinufiya University. The first panel called CCP. This type is a sandwich panel with corrugated core (see Fig. 1). The second sandwich panel is sandwich panel with web core as shown in Fig. 2 and called WCP. The core of this type consist of stiffening metal webs with foam filling the gaps between them but there is no interaction between the filling foam and both of the skins and the web core. The third one is sandwich panel with two-directional corrugated core as shown in Fig. 3 and called TCP. All the geometrical dimensions of the specimens are sandwich structures. They used the force-distortion relationship and the modified stiffness matrix method presented in Table 1 . The specimens were fabricated from the steel sheets with $1000 \times 2000 \times 0.50 \mathrm{~mm}$ dimensions. The stress-strain curve for the used sheet was considered as Darwish (2008) and as shown in Fig. 4. From this curve, the yield stress was considered as $230 \mathrm{MPa}$ corresponding to strain of 0.0011 and modulus of elasticity was considered as $209 \mathrm{GPa}$.

In the current work, new technique was developed to manufacture the sandwich panel. At the first, the bottom and top skin were prepared by cutting the steel sheet with their required dimensions (L\&B). At the second, the cores were fabricated into their shape. In the case of SP1, the core was made by cutting the sheet then it formed to be corrugated with $45^{\circ}$ angle $(\theta)$ by a machine as shown in Fig. 5. For the web core (WCP), the sheet was cut into sixteen parts, each part has $1000 \mathrm{~mm}$ length and $100 \mathrm{~mm}$ width then it was formed to be with channel cross section with $500 \mathrm{~mm}$ core height and $250 \mathrm{~mm}$ flange width as shown in Fig. 6. The core was proved from two channels back to back to increase the stiffness of the web core. The two channels were fixed by rivets. For twodirectional corrugated core (TCP), the sheet was cut into twenty six parts, each part has $1000 \mathrm{~mm}$ length and $400 \mathrm{~mm}$ width then it bent with $45^{\circ}$ angle $(\theta)$ by bending machine to form the required shape and dimension as shown in Fig. 7. At the third, the top and bottom skin were fixed with the core by aluminum blind rivets as shown in Fig. 8. The spacing between blind rivets is $500 \mathrm{~mm}$.

The panels were simply supported at their four sides on four steel rollers which were welded on steel frame as illustrated in Fig. 9. The three sides of sandwich panel were fixed by three channels in each side to reduce the specimens up left at the line support. The load was applied at the center of the panel. The load was increased with $1.0 \mathrm{kN}$ as a cumulative incremental. In each time step, the deflection at the center of the bottom skin of the panel was measured. A steel plate and rubber pad with dimension 100x100 mm were used under the applied load. 


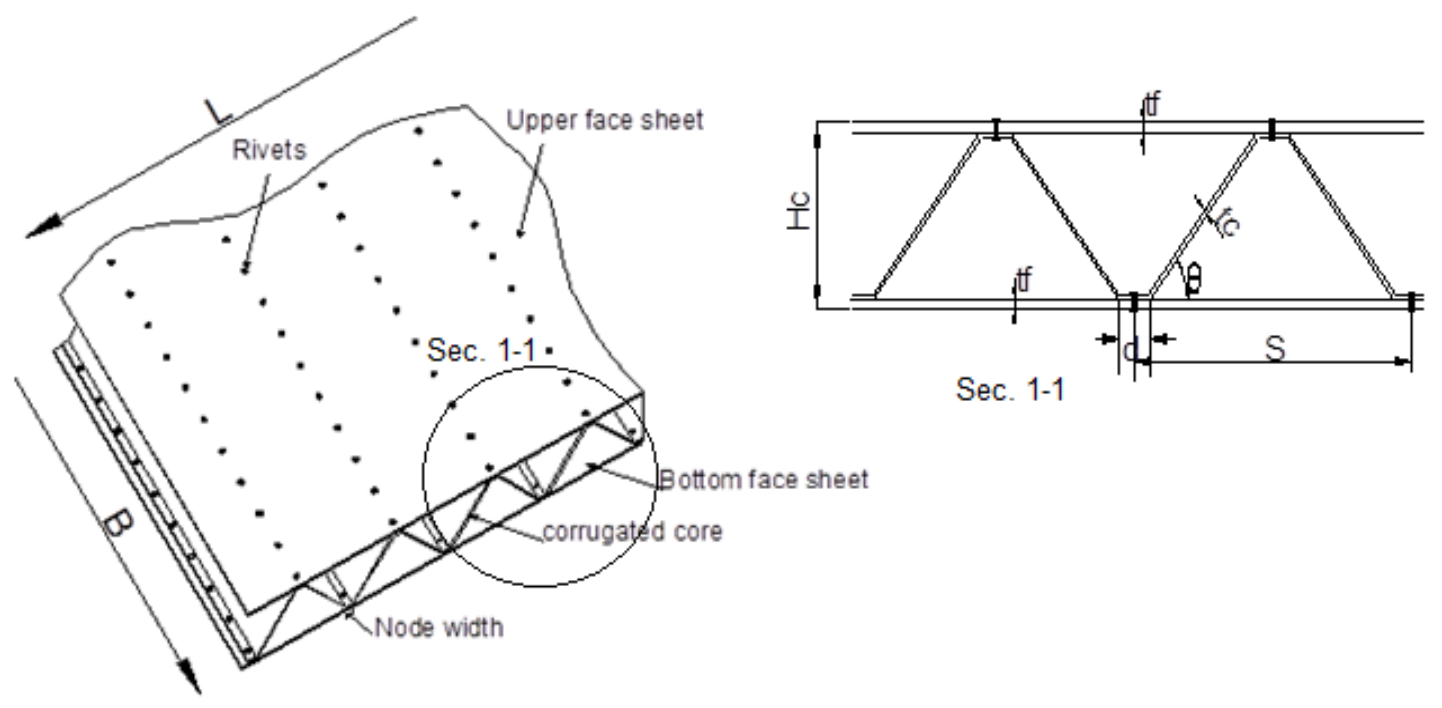

Fig. 1 Sandwich panel with corrugated core (CCP)
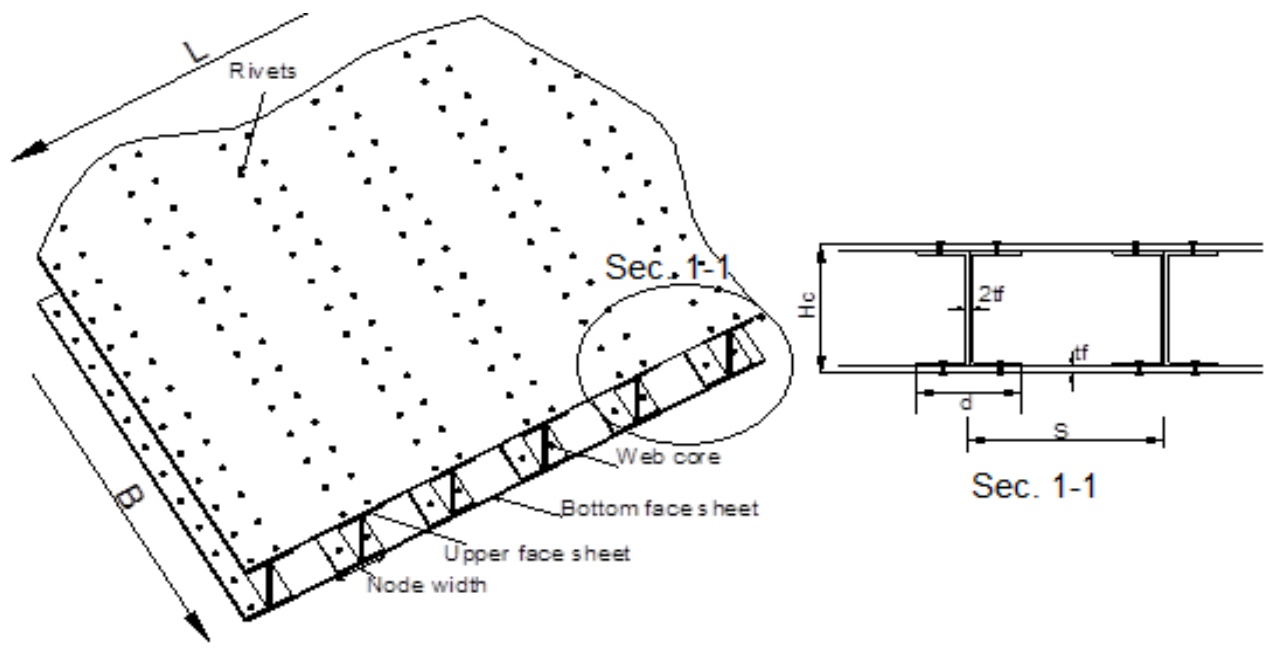

Sec. 1-1

Fig. 2 Sandwich panel with web core (WCP)
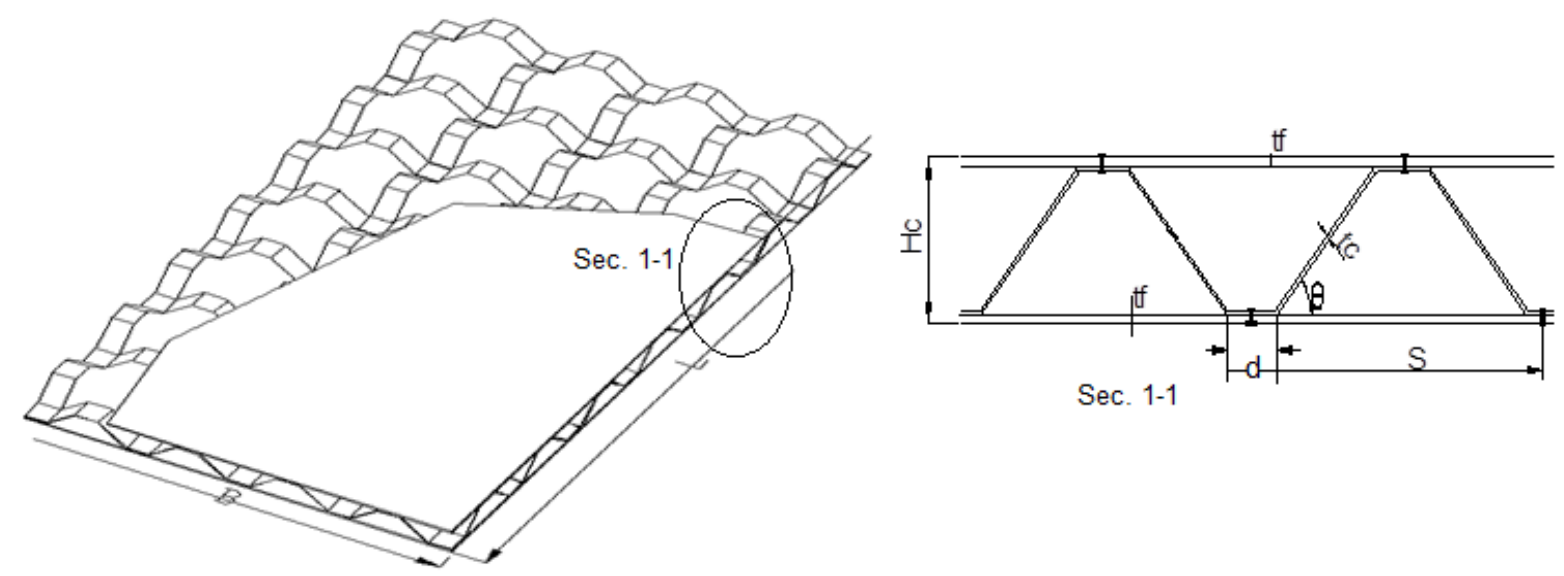

Sec. 1-1

Fig. 3 Sandwich panel with two-directional corrugated core (TCP) 
Table 1 Specimen dimension

\begin{tabular}{cccccccc} 
& $\mathrm{L}$ & $\mathrm{B}$ & $\mathrm{t}_{\mathrm{f}}$ & $\mathrm{t}_{\mathrm{c}}$ & $\mathrm{s}$ & $\mathrm{H}_{\mathrm{c}}$ & $\mathrm{d}$ \\
& & & & & & & \\
\hline $\mathrm{CCP}$ & 970 & 1000 & 0.5 & 0.5 & 110 & 50 & 10 \\
\hline WCP & 1000 & 1000 & 0.5 & 0 & 125 & 50 & 50 \\
\hline TCP & 1000 & 1000 & 0.5 & 0.5 & 180 & 50 & 40
\end{tabular}

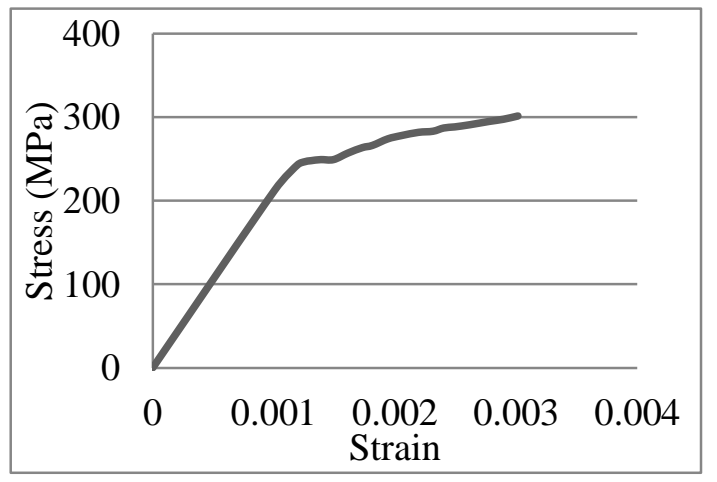

Fig. 4 Stress-strain behavior of steel

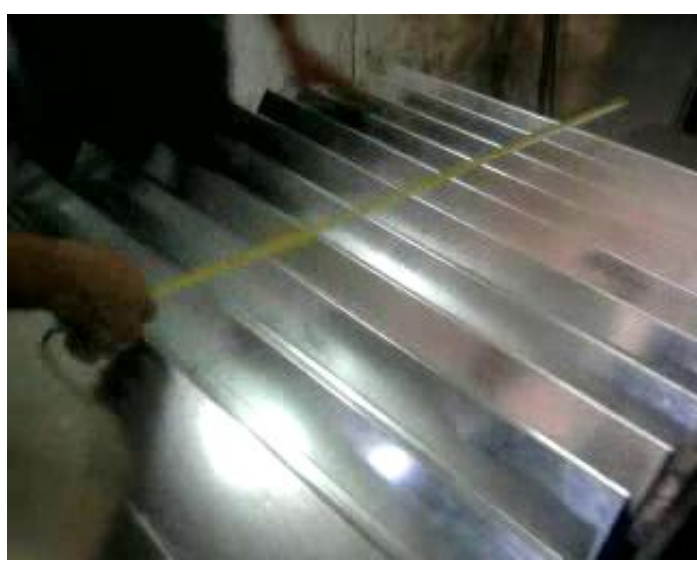

Fig. 5 Manufacturing and arrangement process of corrugated core

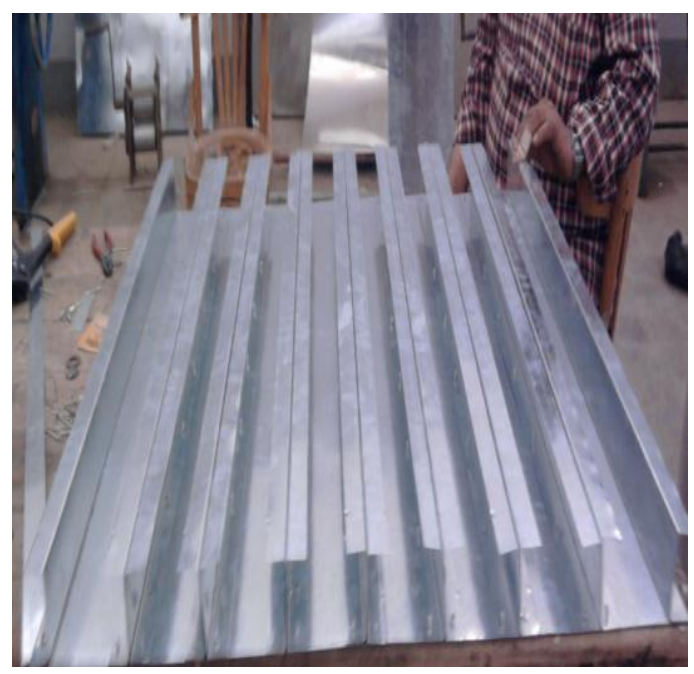

Fig. 6: Arrangement and manufacturing process of WCP

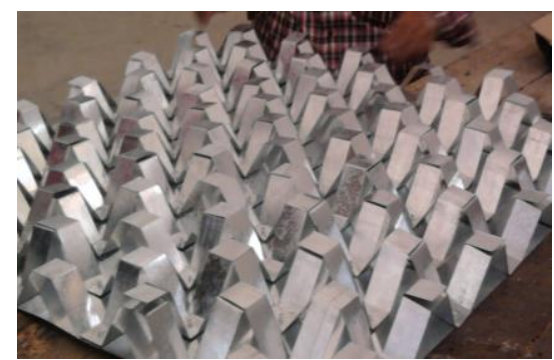

Fig. 7 Manufacturing process of corrugated core

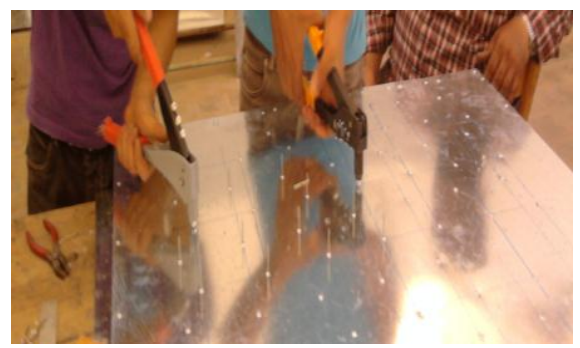

Fig. 8 Fixed rivets of TCP

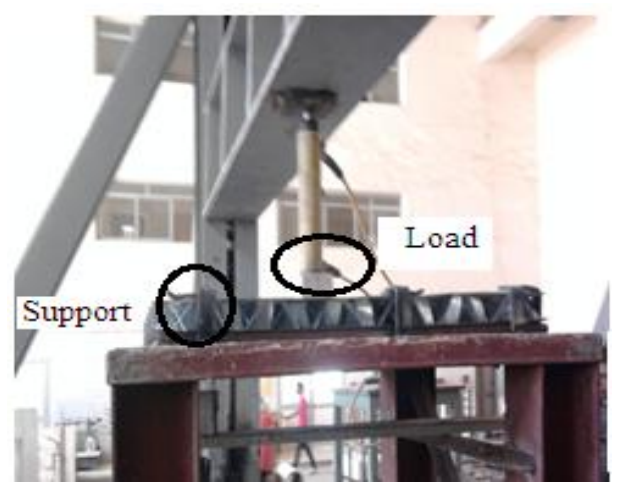

Fig. 9 Specimen test

\section{3- FE Model}

A general purpose finite element ANSYS (2006) program was utilized in the current research to simulate the sandwich panels and it determines their behavior up to failure. Shell181 elements were used to represent the panel. Shell181elemen is suitable for analyzing thin to moderately-thick shell structures. It is well-suited for linear-large rotation and large strain nonlinear application. It may be used for layered applications for modeling laminated composite shell or sandwich construction. It has four nodes. Each node has six degree of freedom (dof); translation in $\mathrm{X}, \mathrm{Y}$ and $\mathrm{Z}$ direction and rotation about $\mathrm{X}, \mathrm{Y}$ and $\mathrm{Z}$ axes (see Fig. 10). In the current research, the panels are loaded up to failure so that the nonlinear material analysis (plasticity) is reached. The material nonlinearity was represented by Multilinear Kinematic Hardening Constants (MKIN). It assumes the total stress range is equal to twice the yield stresses, so that Bauschinger effect is included. MKIN may be used for materials that obey von Mises yield criteria. Von Mises yield criteria includes most metals. The material behavior was described by a stress-strain curve as presented in Fig. 4. It starts at the original and it is with positive stress and strain 
values. The initial slope of the curve is represented the elastic modulus of the material.

In ANSYS (2006) nonlinear analysis, two different techniques may be used. The first technique is loadcontrol technique. In this technique, total load is applied to a finite element model. The load is divided into a series of load increments during the analysis called load steps. The second techinque is displacement-control technique. In this techniqe, the displacement is appleied to the model and the displacement is divided into a series of increments called load steps. The load steps is defined by program user. With increasing the number of load steps, the accuracy of results is increased and the program needs a large time to complete the solution. After completing each increment, the stiffness matrix of the model is adjusted to reflect nonlinear changes in structural stiffness. This changes occure before proceeding to the next load increment (refer to Singh [94]). In the current analysis, load -control technique is used.

The ANSYS (2006) uses Newton-Raphson method for updating the model stiffness (see Fig. 11). Before each solution, the Newton-Raphson method evaluates the out-of-balance load vector. The out-of-balance load vector is the difference between the restoring forces (the load corresponding to the element stresses) and the applied loads. The program then performs a linear solution, using the out-of-balance loads, and checks for convergence. If convergence criteria are not satisfied, the out-of-balance load vector is re-evaluated, the stiffness matrix is updated, and a new solution is obtained. This iterative procedure continues until the solution converges. A number of convergence-enhancement and recovery features, such as line search and automatic load stepping can be activated to help the problem to converge. If convergence cannot be achieved, then the program attempts to solve with a smaller load increment. In the current analysis, the displacementcontrol technique is selected. The finite element models for the three types of the sandwich panels are presented in Fig. 12.

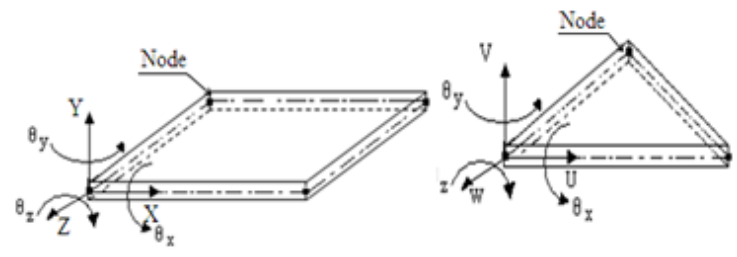

a) Rectangular shell element

b) Triangular shell element

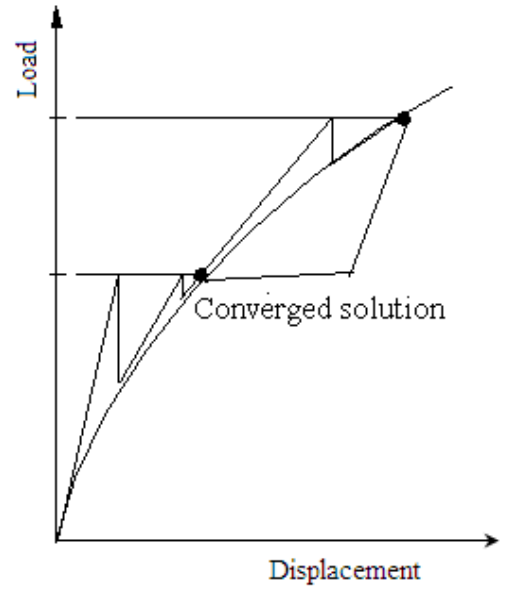

Fig. 11 Newton-Raphson method

\section{4- RESULTS AND DISCUSSIONS}

In the current section, the comparisons between the numerical and experimental results are presented and discussed. Fig. 13 presents load- deflection curve for $\mathrm{CCP}$ as measured from the current experimental work and obtained from the numerical model. From this figure, particularly good agreement is seen between the experimental work and the numerical simulation until $10 \mathrm{kN}$ applied load and after that the difference between the experimental and numerical results are increased to be $7 \%$. The shape of failure at the total collapse load of CCP from the experimental work and the numerical model are shown in Fig. 14 and Fig. 15; respectively. From the experimental work, the numerical model and the two previous Figures $(11 \& 12)$, it can be noted that the failure of the panel was started at $7 \mathrm{kN}$ total load as intercellular buckling in the top face and the corrugated core under the location of the applied load and with increasing the load the intercellular buckling transferred to the neighboring parts of the core until failure. Also it can be concluded that the intercellular buckling accrues at the line parallel to the support edge and parallels to the direction of the corrugation in the core.

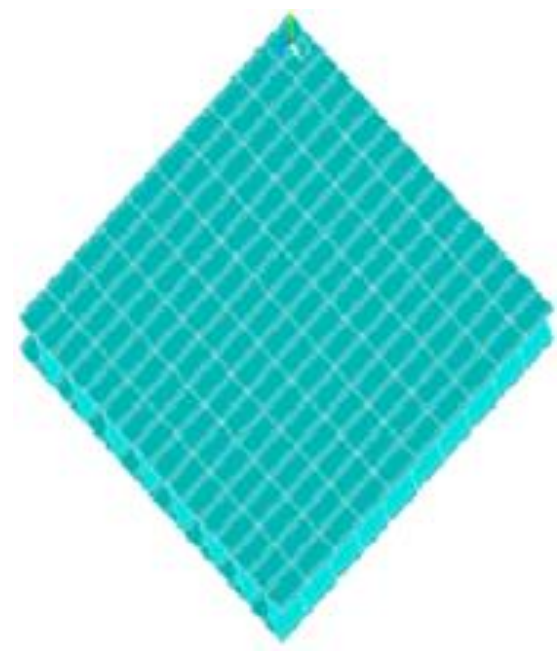


a) $\mathrm{CCP}$

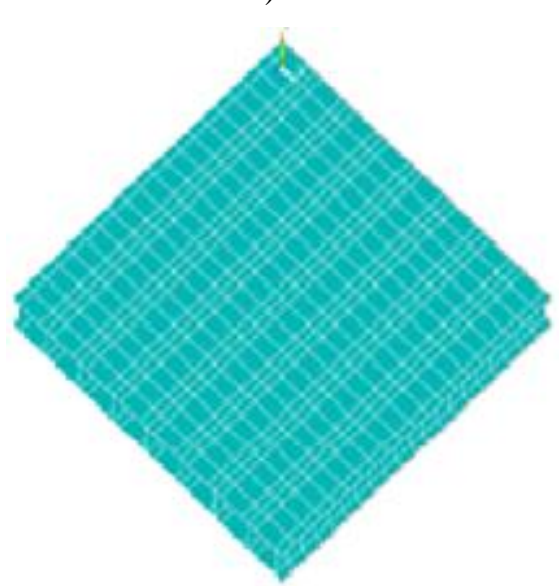

b) WCP

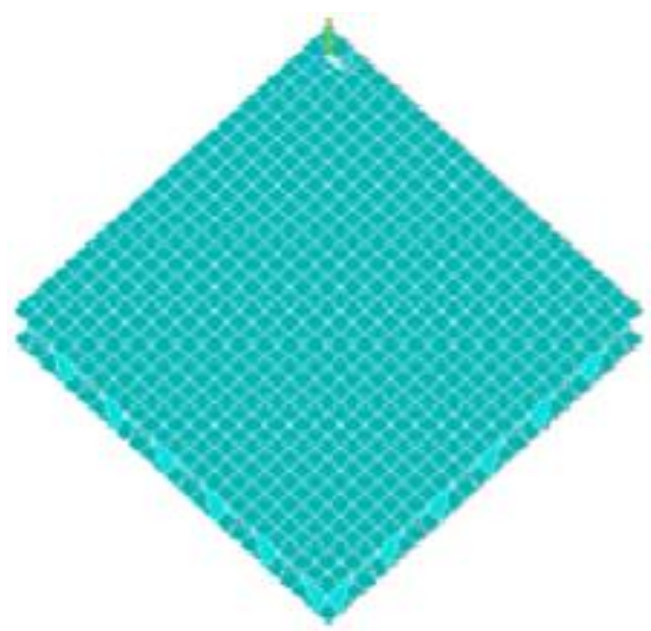

c) $\mathrm{TCP}$

Fig. 12 Numerical models for the tested sandwich panel

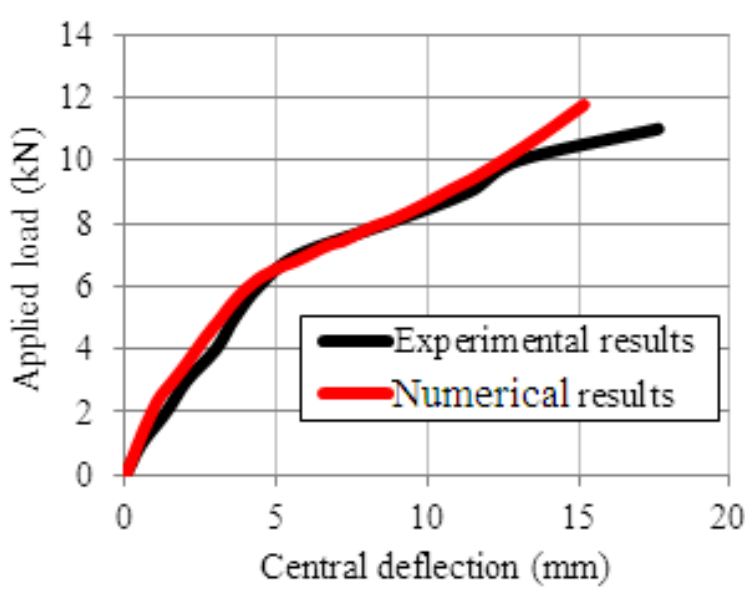

Fig. 13 Comparison between experimental and numerical load deflection curve for CCP panel tested

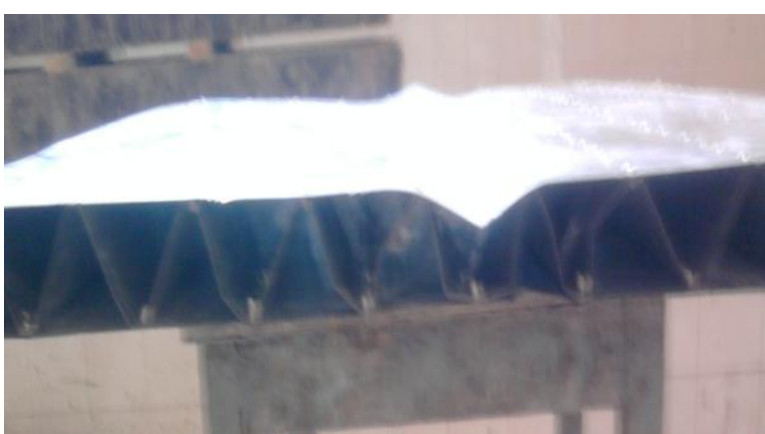

Fig. 14 Experimental mode of failure for CCP Panel

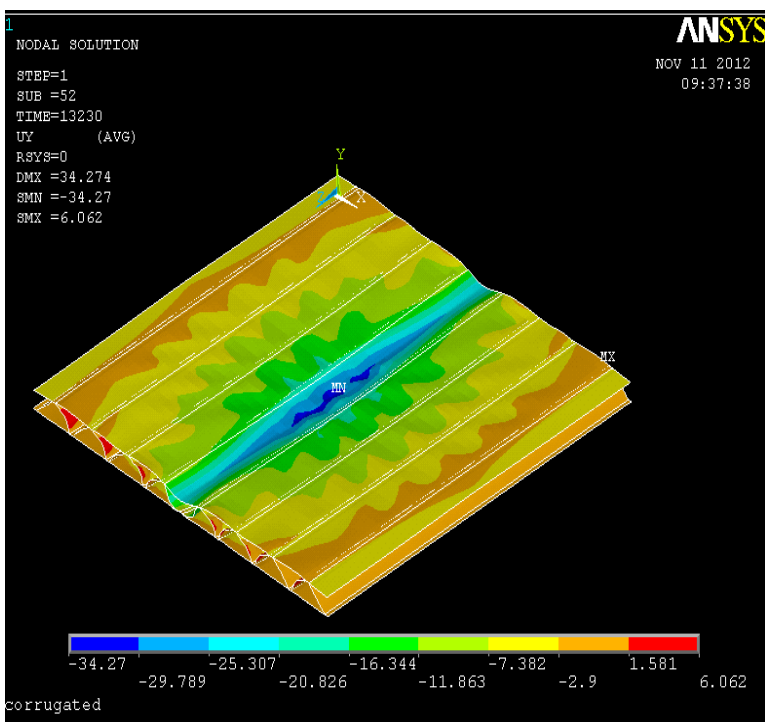

Fig. 15 Numerical deflection at the failure load for CCP The relationship between the experimental and numerical applied load and deflection for WCP panel is presented in Fig. 16. The failure model for this panel from the experimental work and its simulation finite element model are illustrated in Fig. 17 and Fig. 18; respectively. From Fig. 16, it can be noted that the panel failed at $16 \mathrm{kN}$ failure load and 15.5 $\mathrm{mm}$ central deflection as obtain from the experimental results. Also from this figure, it can be concluded that the load-deflection curve from the current developed finite element model for WCP is closed to load-deflection curve at this joint from the experimental results. From Fig. 17, the panel failure occurs in the top face under the point load and the presence of foam in the core decreases the deflection (intercellular buckling) in the top face. From Fig. 18, it can be clearly seen that the failure mode occurs in the top face as intercellular buckling and also it can be noted that the intercellular buckling increases in the numerical model in comparing with the failure mode from the experimental results. This is because the foam in the core did not insert in the simulation finite element model.

Fig. 19 shows numerical and experimental load central deflection at the bottom skin curve for TCP. This figure shows that the failure happened at load and deflection approximately equal to $6 \mathrm{kN}$ and 12.5 
$\mathrm{mm}$; respectively from the experimental tests. Also the failure happened at point load and deflection approximately equal to $6.8 \mathrm{kN} 11.5 \mathrm{~mm}$; respectively. The failure behavior was found due to the intercellular buckling of the top skin and the core from the experimental and results as shown in Fig. 20 and Fig. 21; respectively. From the three figures, it can be concluded that the finite element analysis shows a good agreement with the experimental test.

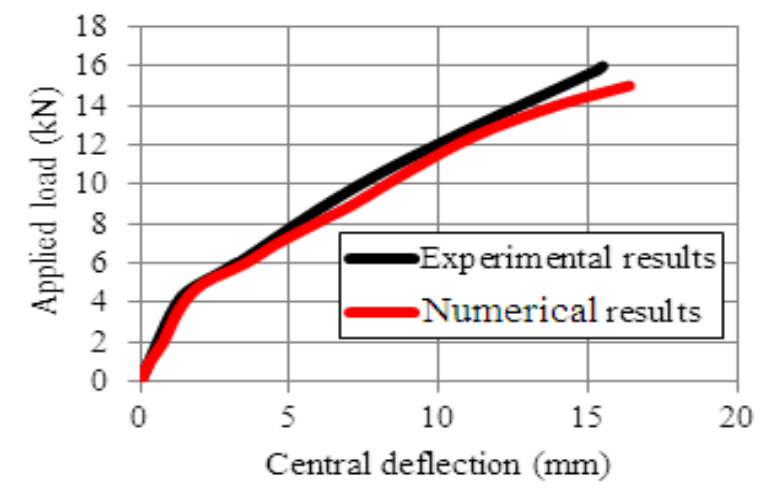

Fig. 16: Comparison between experimental and numerical load deflection curve for WCP panel tested

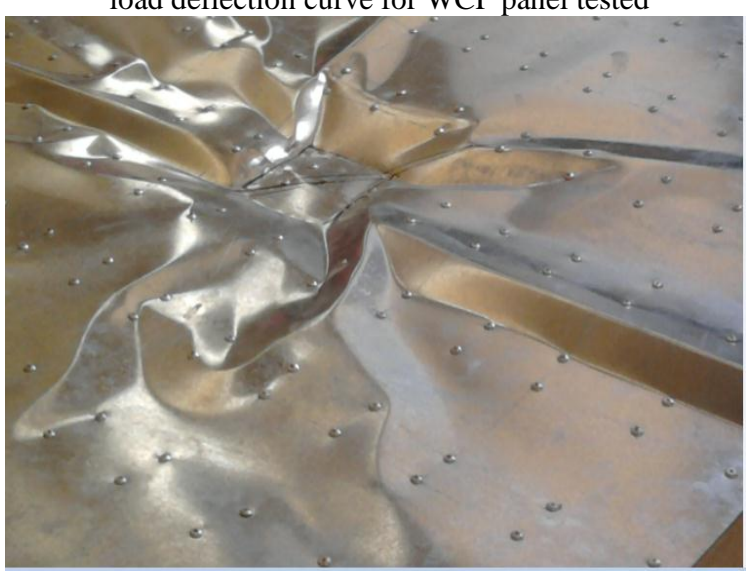

Fig. 17 Experimental mode of failure for WCP panel tested

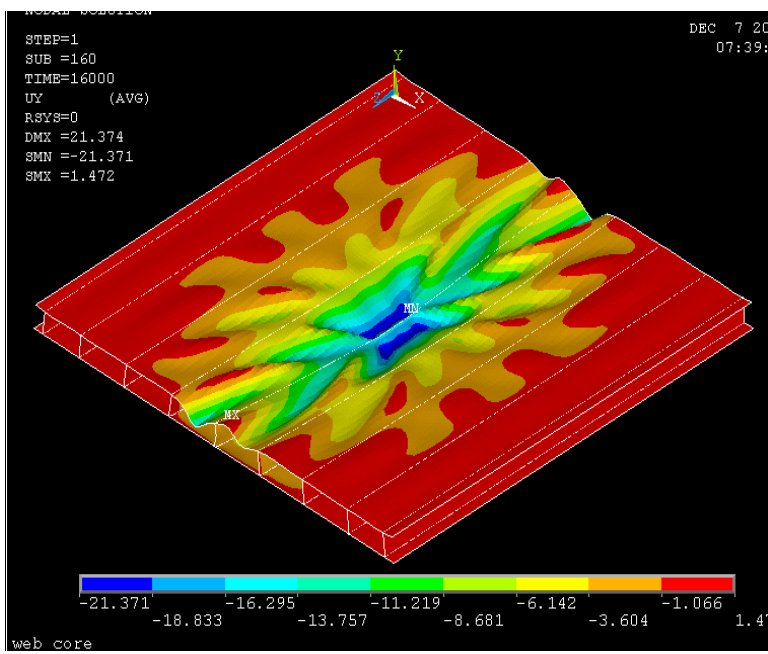

Fig. 18 Deflection from numerical analysis at the failure load for WCP panel

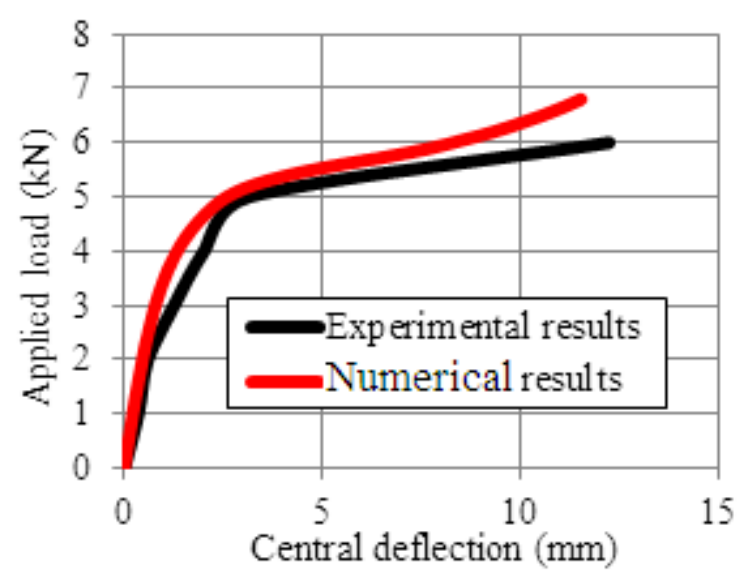

Fig. 20: Comparison between experimental and numerical load deflection curve for TCP panel tested

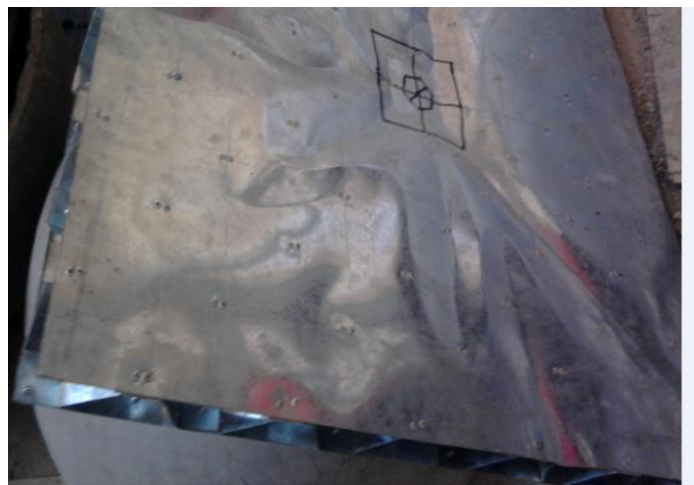

Fig. 21 Experimental mode of failure for TCP panel tested

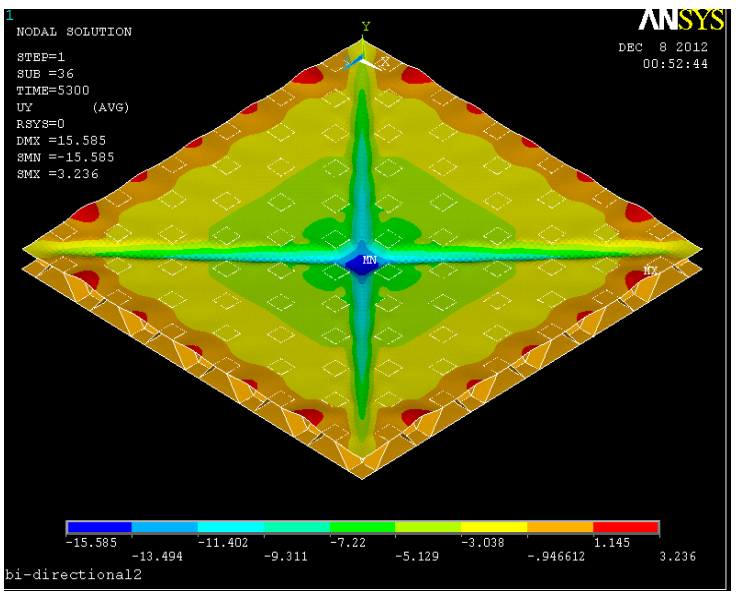

Fig. 22 Deflection from numerical analysis at the failure load for TCP panel

\section{5- CONCLUSIONS}

The present work investigated the experimental and numerical analysis of three different types of sandwich floor panel under point load; sandwich panel with corrugated core, sandwich panel with web core and sandwich panel with two-directional corrugated core. From the results of the experimental work and numerical model, it can be noted that the failure mode in CCP panel is due to intercellular buckling in the top skin and core at the line parallel to the support edge and parallels to the direction of 
the corrugation in the core. Furthermore for the WCP panel the intercellular buckling phenomena occur at the top face under the point load and the presence of foam in the core decreases the top skin deflection as noted from the experimental results. On the other hand, the top skin deflection increases as obtained from the model because the foam did not simulate in the model. For TCP panel, the intercellular buckling happened in the top skin and the core in diagonal direction. It started from the point load and toward to the four corners of the panel. Also it can be concluded that the de-bonding failure between the top or bottom skin and the core does not occur. In general, it can be concluded that the non-linear FE analysis gives a good outcome compared to the experimental test.

\section{REFERENCES}

1. Langhorst, B. R., (2008) "The development of optimal light weight truss-core sandwich panels," Ph.D. Dissertation, California Irvine University, USA.

2. Liu, T., Deng, Z., and Lu, T., (2008) "Analytical modeling and finite element simulation of the plastic collapse of sandwich beams with pinreinforced foam cores," Inter. J. Solids Struct., 45, 5127-5151.

3. Manalo, A., Aravinthan T., Karunasena, W., and Islam, M., (2010) "Flexural behavior of structural fiber composite sandwich beams in flatwise and edgewise positions," J. Compos. Struct., 92, 984-995.

4. Awad, Z., Thiru-Aravinthan, T., and Zhuge, Y., (2012) "Experimental and numerical analysis of an innovative GFRP sandwich floor panel under point load," J. Eng. Struct., 41, 126-135.

5. Engin, M., and Rizkalla, S., (2008) "Material characteristics of 3-D FRP sandwich panels," $J$. Const. and Build. Mater., 22, 1009-1018.

6. Fam, A., and Sharaf, T., (2010) "Flexural performance of sandwich panels comprising polyurethane core and GFRP skins and ribs of various configurations," J. Compos. Struct., 92, 2927-2935.

7. Godfrey, S. W. (2010) "Optimal design of orthotropic fiber-composite corrugated-core sandwich panels under axial compression," M.Sc. Thesis, California Irvine University, USA.

8. El-Sayed, E. A. and Basily, B. B., (2004) "A continuous folding process for sheet materials," Inter. J. Mater. Prod. Techno., 21(3), 217-238.
9. Sokolinsky, V., and Frostig, Y., (2000) "Branching behavior in the nonlinear response of sandwich panels with a transversely flexible core," Inter. J. Solid. Struct., 37, 5745-5772.

10. Frostig, Y., (2003) "Classical and high-order computational models in the analysis of modern sandwich panels," Compos., Part B, 34, 83-100.

11. Frostig, Y., (2009) "Elastica of sandwich panels with a transversely flexible core-a high-order theory approach," Inter. J. Solid. Struct., 46, 2043-2059.

12. Briscoe, C., Mantell, S., and Davidson, J., (2010) "Shear buckling in foam-filled web core sandwich panels using a Pasternak foundation model," J. Thin-Walled Struct., 48, 460-468.

13. Pokharel, N., and Mahendran, M., (2004) "Finite element analysis and design of sandwich panels subject to local buckling effects," J. Thin-Walled Struct., 42, 589-611.

14. Leekitwattana, M., Boyd, S. W., and Shenoi, R. A., (2011) "Evaluation of the transverse shear stiffness of a steel bi-directional corrugated-stripcore sandwich beam" J. Constr. Steel Resear., 67, 248-254.

15. Jeffrey, P., Senthil, V., and Vincent, C., (2013) "Multi-objective optimization of laser-welded steel sandwich panels for static loads using a genetic algorithm," J. Eng. Struct., 49, 508-524.

16. Hadi, K., and Matthews, L., (2000) "Development of Benson-Mayers theory on the wrinkling of anisotropic sandwich panels," Compos. Struct., 49, 425-434.

17. Gdoutos, E. E., Daniel, I. M., and Wang, K., A., (2003) "Compression facing wrinkling of composite sandwich structures," J. Mech. Mater., 35, 511-522.

18. Pokharel, N., and Mahendran, M., (2005) "An investigation of lightly profiled sandwich panels subject to local buckling and flexural wrinkling effects," J. Constr. Steel Resear., 61, 984-1006.

19. Biagi, R., and Smith, H., (2012) "In-plane column response of metallic corrugated core sandwich panels," Inter. J. Solid. Struct., 49(26), 39013914.

20. ANSYS (2006), "Help and manual," $12^{\text {th }}$ Editor, ANSYS Inc, PA, USA.

21.Darwish, F., (2008) "Flexural behavior of steel web core sandwich panels," M.Sc. Thesis, King Fahd University of Petroleum and Minerals, Sauda Arabia. 